\title{
ORÇAMENTO CUSTEIO DAS INSTITUIÇÕES DE ENSINO SUPERIOR NO BRASIL
}

José Nilton Leite de Oliveira ${ }^{1}$, Armando Araújo de Souza Junior ${ }^{2}$

\section{Resumo}

Para a sustentabilidade financeira das Instituições de Ensino Superior é fundamental otimizar a alocação estratégica dos custos do serviço de educação, diante desse contexto, este trabalho apresenta uma análise da literatura sobre orçamento custeio e tem como objetivo apresentar um estudo sobre os modelos de orçamento custeio de Instituições de Ensino Superior no Brasil. O estudo foi conduzido por meio de uma pesquisa qualitativa, exploratória descritiva, pesquisa documental e bibliográfica. Foi realizada em dezembro de 2018 e analisou 485 publicações, dentre as quais artigos, dissertações e teses, nas bases de dados eletrônicas Portal de Periódicos CAPES/MEC, Rede SciELO e Google Acadêmico. Foram analisados, também, relatórios estruturados de cinco empresas do segmento Serviços Educacionais listadas na Bovespa. As principais conclusões retratam que: (a) as Instituições Públicas de Ensino Superior adotam, com algumas variações, o modelo proposto pelo MEC e proposto pela Associação Nacional de Dirigentes das Instituições Federais de Ensino Superior (ANDIFES); (b) há um alto grau de dificuldade em obter dados para a pesquisa relacionados as Instituições Privadas de Ensino Superior, visto que as informações são de natureza gerencial, ou seja, são informações de cunho estratégicos para o crescimento da empesa.

Palavras-chaves: Orçamento custeio. Alocação orçamentária. Rateio orçamentário.

\begin{abstract}
For the financial sustainability of the Institutions of Higher Education, it is fundamental to optimize the strategic allocation of the costs of the education service, in view of this context, this work presents an analysis of the literature on budget costing and aims to present a study on the budget models costing Institutions of Higher Education in Brazil. The study was conducted through qualitative, exploratory descriptive research, documental and bibliographic research. It was held in December 2018 and analyzed 485 publications, among which articles, dissertations, and theses, in the electronic databases Portal de Periodicals CAPES / MEC, SciELO Network, and Google Academic. We also analyzed structured reports of five companies from the Educational Services segment listed on the Bovespa. The main conclusions show that: (a) Public Institutions of Higher Education adopt, with some variations, the model proposed by the MEC and proposed by the National Association of Directors of Federal Institutions of Higher Education (ANDIFES); (b) there is a high degree of difficulty in obtaining data for research related to Private Institutions of Higher Education, since the information is managerial in nature, that is, it is strategic information for the growth of the company.
\end{abstract}

\footnotetext{
${ }^{1}$ Pós-Graduação - Mestrado em Engenharia da Produção - Universidade Federal do Amazonas - UFAM jotanil@hotmail.com

${ }^{2}$ Universidade Federal do Amazonas - UFAM - armando-jr07@bol.com.br
} 
Key-words: Budgeting cost. Budget allocation. Budgetary assessment.

\section{INTRODUÇÃO}

A educação superior do Brasil vem sofrendo significativas mudanças na legislação. Em 2004 o governo brasileiro promulgou a Lei 10.861 que institui o Sistema Nacional de Avaliação da Educação Superior (SINAES), o qual inclui nesse processo avaliativo o planejamento estratégico, mais conhecido no meio acadêmico como o Plano de Desenvolvimento Institucional - PDI (BRASIL, 2004a).

Para as instituições de ensino superior (IES) o Plano de Desenvolvimento Institucional é um documento onde estão definidas a missão e as estratégias para se atingir as metas e objetivos traçados (BRASIL, 2004b) e é um dos principais instrumentos de planejamento e gestão. Através do PDI se propõe um estudo para um período de cinco anos e nele contempla, além de outros fatores, o cronograma, a metodologia de implementação dos objetivos e o orçamento (GRIBOSKI et al., 2018).

O artigo terceiro da referida Lei, que institui o Sistema Nacional de Avaliação da Educação Superior - SINAES, destaca "a missão e o plano de desenvolvimento institucional" (BRASIL, 2004a) como sendo o primeiro quesito a ser objeto de avaliação, ressaltando, dessa forma, o valor que o PDI possui para o sistema de avaliação das instituições de ensino superior.

O Plano de Desenvolvimento Institucional é o documento formal da IES que retrata o planejamento estratégico e é utilizado em diversas etapas da vida da IES, tais como: processo de credenciamento, recredenciamento e avaliação. Estabelece e institucionaliza o caminho que a IES pretende percorrer em termos de visão, de estrutura das atividades cotidianas e de objetivos a serem perseguidos.

Outro ponto importante na apresentação do PDI são os aspectos financeiros e orçamentários, pois dentre os diversos elementos que deve conter no PDI, conforme o inciso X, do art. 21 do Decreto N N $^{\circ}$.235, de 15 de dezembro de 2017, (BRASIL, 2017a) a IES deve demonstrar sua capacidade e sustentabilidade financeira.

Aliado a isso as instituições de ensino superior no Brasil enfrentam grandes dificuldades associadas ao alto custo de manutenção de seus cursos. Para manter ensino, pesquisa e extensão são necessários um grande número de profissionais altamente qualificados e seus gastos com pessoal representam uma parte significativa no orçamento da IES.

Na tomada de decisões financeiras, um dos mais importantes instrumentos utilizados é o orçamento empresarial. 
No entanto poucas pesquisas são realizadas sobre esse tema para instituições privadas de ensino superior. A abordagem sobre rateio orçamentário é tratada de maneira superficial em pesquisas que versam sobre Planejamento Estratégico. Nesse sentido é essencial que planejamento estratégico e a execução orçamentária da organização estejam integrados.

Como sustentam Chang e Chao (2016), o orçamento é sempre o primeiro passo para planejar as soluções. Portanto, é necessário discutir sobre como alocar adequadamente os fundos disponíveis para atingir o objetivo de seus projetos. E vão além, quando afirmam que a eficiência financeira é o elemento chave que deve ser alcançado através de orçamentos eficazes.

No entanto, é importante frisar que aplicar recursos escassos para otimizar a eficiência do serviço de educação, a alocação estratégica dos custos é fundamental para a sustentabilidade financeira das IES.

Diante desse contexto, este trabalho apresenta uma análise da literatura sobre orçamento custeio, tendo como questão norteadora da pesquisa: "Como são executados o rateio orçamentário das Instituições de Ensino Superior do Brasil?”

Nessa direção, este estudo objetiva apresentar um estudo sobre os modelos de orçamento custeio de Instituições de Ensino Superior no Brasil. Este trabalho pretende, ainda, identificar o processo de gestão orçamentária das IES; analisar a metodologia adotada pelas IES quanto a execução orçamentária; e apresentar os modelos que já estão consolidados e disponíveis na literatura.

O trabalho foi dividido em cinco partes, incluindo esta introdução. Na segunda parte será apresentado o referencial teórico sobre Orçamento e Gestão de Custos. A terceira parte refere-se ao campo da pesquisa e aos procedimentos metodológicos que nortearam a realização da coleta de dados e, em seguida, a quarta parte descreve os resultados obtidos com a pesquisa e nas considerações finais serão apresentadas as conclusões e contribuições deste estudo.

\section{MATERIAL E MÉTODOS}

O propósito desta pesquisa foi apresentar um estudo sobre os modelos de orçamento custeio das Instituições de Ensino Superior no Brasil, para isso adotou-se uma pesquisa qualitativa, exploratória descritiva, pesquisa documental e bibliográfica, que é um estudo estruturado e desenvolvido a partir de material publicado em livros, revistas, jornais, redes eletrônicas (KNECHTEL, 2014), portanto, é um material acessível ao público em geral.

O estudo foi dividido em duas etapas: na primeira fase foi realizada uma pesquisa bibliográfica, que consistiu no ato de identificar, filtrar, selecionar, ler, analisar e organizar por 
tópicos relacionados à gestão de custos, gestão orçamentária e planejamento estratégico das instituições de ensino superior, seguindo o fluxo de seleção conforme Figura 1.

Figura 1: Diagrama do fluxo de seleção de artigos

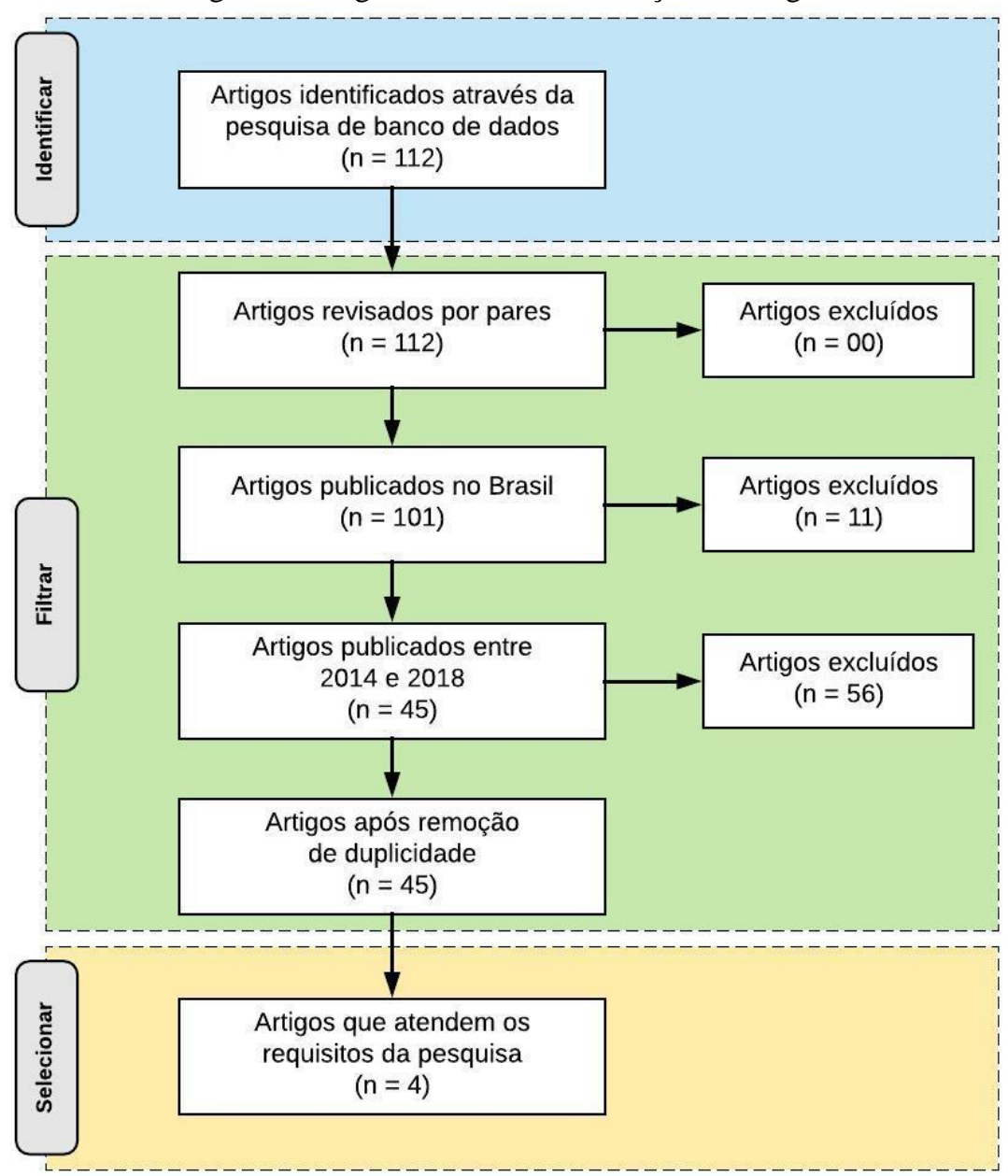

Fonte: Elaborado pelos autores, 2018

A segunda fase foi uma pesquisa de informações sobre o setor de ensino superior no Brasil, utilizando como fontes: artigos publicados em congressos, jornais e revistas especializadas; sítio eletrônico de instituições governamentais e de associações privadas de ensino superior; livros e artigos publicados por instituições governamentais como o Instituto Nacional de Estudos e Pesquisas Educacionais (INEP) e o Ministério da educação (MEC); estatísticas produzidas pelo Instituto Brasileiro de Geografia e Estatística (IBGE); e relatórios trimestrais e anuais de empresas abertas do setor de ensino disponíveis no sítio eletrônico da Comissão de Valores Mobiliários (CVM); e webnários de executivos de empresas do setor colhidas na mídia.

Os artigos foram selecionados adotando os seguintes critérios: (1) se a revisão do manuscrito científico publicado foi realizada por pares, uma vez que a revisão paritária tem 
como consequência maior visibilidade perante a sociedade (WERLANG, 2013); (2) se o artigo foi publicado no Brasil, tendo em vista que o foco do estudo está relacionado às instituições de ensino nacionais; e (3) se o escrito é atual, ou seja, se o artigo foi publicado nos últimos cinco anos, no período de 2014 a 2018.

A pesquisa foi realizada em dezembro de 2018 e analisou 485 publicações, dentre as quais artigos, dissertações e teses, em três bases de dados bibliográficas eletrônicas e informações repositórios (Portal de Periódicos CAPES/MEC, Rede SciELO e Google Acadêmico), além de relatórios e apresentações aos investidores de cinco empresas listadas no sítio eletrônico da Brasil Bolsa Balcão, do Setor Consumo Cíclico, Segmento Serviços Educacionais. Foram analisados quantitativa e qualitativamente as seguintes variáveis: quantidade de publicações; características de avaliação dos artigos; locais de publicação; período de publicação; autores; instituições de ensino; palavras-chave; e temas.

Os dados foram colhidos no endereço eletrônico do Portal de Periódicos CAPES/MEC, Rede SciELO e Google Acadêmico e sítios das empresas analisadas, posteriormente elaborouse uma planilha eletrônica, utilizando-se o software Excel da Microsoft, que foi estruturada com os seguintes campos: Resultado Inicial, Revisados por Pares, (Localização) Brasil, (Período de publicação de ) 2014 a 2018 e Resultado Final. As representações gráficas foram feitas usando software Excel da Microsoft e as ilustrações utilizando o software Lucidchart. O tratamento dos dados serviu de aporte para as análises, resultando nas informações que serão apresentadas mais adiante.

\section{RESULTADOS E DISCUSSÃO}

O Censo da Educação Superior é realizado anualmente pelo Instituto Nacional de Estudos e Pesquisas Educacionais Anísio Teixeira (Inep) considerado um importante instrumento de produção de informações que são utilizadas para sustentar a formulação, o monitoramento e a avaliação das políticas públicas, além disso, é uma ferramenta que subsidia pesquisadores e estudiosos no do setor (BRASIL, 2017b), nesse sentido, torna-se relevante destacar um recorte do cenário da educação no Brasil.

Das 2.448 Instituições de Ensino Superior, 2.152 são privadas o que equivale a 87,9\% do total, enquanto que $12,1 \%$ desse total (296), são públicas e estão divididas entre estaduais $(5,1 \%)$, federais $(4,5 \%)$ e municipais $(2,6 \%)$, conforme demonstrado no Gráfico 1. 
Gráfico 1: Instituições de Educação Superior, por categoria administrativa

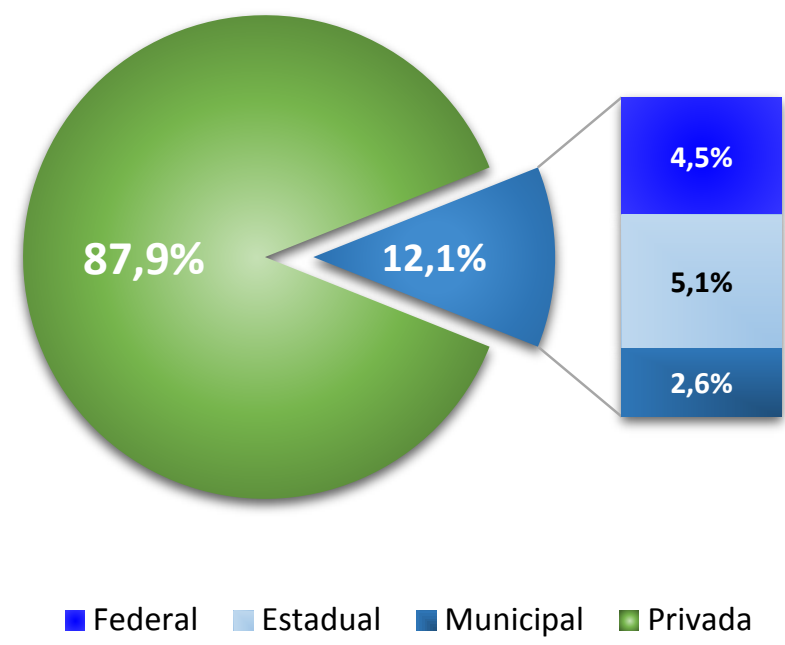

Fonte: BRASIL/MEC/INEP, 2017

Um dado que chama a atenção na Tabela 1, é que a maioria das universidades são públicas, respondendo por $53,3 \%$, em contrapartida, o que predomina nas IES privadas são as faculdades, correspondendo a $87,3 \%$.

Tabela 1 - Número de Instituições de Ensino Superior, por Organização Acadêmica e Categoria Administrativa - Brasil - 2006-2017

\begin{tabular}{|c|c|c|c|c|c|c|c|c|c|}
\hline \multirow{3}{*}{ Ano } & \multicolumn{9}{|c|}{ Instituições } \\
\hline & \multirow{2}{*}{ Total } & \multicolumn{2}{|c|}{ Universidade } & \multicolumn{2}{|c|}{ Centro Universitário } & \multicolumn{2}{|c|}{ Faculdade } & \multicolumn{2}{|c|}{ IF e Cefet } \\
\hline & & Pública & Privada & Pública & Privada & Pública & Privada & Pública & Privada \\
\hline 2006 & 2.270 & 92 & 86 & 4 & 115 & 119 & 1.821 & 33 & a \\
\hline 2007 & 2.281 & 96 & 87 & 4 & 116 & 116 & 1.829 & 33 & a \\
\hline 2008 & 2.252 & 97 & 86 & 5 & 119 & 100 & 1.811 & 34 & $\mathrm{a}$ \\
\hline 2009 & 2.314 & 100 & 86 & 7 & 120 & 103 & 1.863 & 35 & $\mathrm{a}$ \\
\hline 2010 & 2.378 & 101 & 89 & 7 & 119 & 133 & 1.892 & 37 & $\mathrm{a}$ \\
\hline 2011 & 2.365 & 102 & 88 & 7 & 124 & 135 & 1.869 & 40 & $\mathrm{a}$ \\
\hline 2012 & 2.416 & 108 & 85 & 10 & 129 & 146 & 1.898 & 40 & $\mathrm{a}$ \\
\hline 2013 & 2.391 & 111 & 84 & 10 & 130 & 140 & 1.876 & 40 & $\mathrm{a}$ \\
\hline 2014 & 2.368 & 111 & 84 & 11 & 136 & 136 & 1.850 & 40 & $\mathrm{a}$ \\
\hline 2015 & 2.364 & 107 & 88 & 9 & 140 & 139 & 1.841 & 40 & $\mathrm{a}$ \\
\hline 2016 & 2.407 & 108 & 89 & 10 & 156 & 138 & 1.866 & 40 & $\mathrm{a}$ \\
\hline 2017 & 2.448 & 106 & 93 & 8 & 181 & 142 & 1.878 & 40 & $\mathrm{a}$ \\
\hline
\end{tabular}

Fonte: Brasil, 2017 
Nota: (a) Não se aplica

Legenda:

IF - Instituto Federal

Cefet - Centro Federal de Educação Tecnológica

No que tange ao rateio orçamentário das IES foi abordado sob duas perspectivas bem distintas: A primeira abordagem trata das Instituições Públicas de Ensino Superior e a segunda das Instituições Privadas de Ensino Superior.

Estudos recentes no Brasil (REIS et al., 2017; SANTOS e MOURA, 2017; ARAÚJO et al., 2018) demonstram que o rateio orçamentário elaborado pelas Instituições Federais de Ensino Superior (IFES) tem como base um modelo matemático estabelecido pelo MEC e proposto pela Associação Nacional de Dirigentes das Instituições Federais de Ensino Superior (ANDIFES). Esse modelo leva em consideração, dentre outras variáveis, o desempenho acadêmico da instituição e busca induzir as IFES a adotar procedimentos de gestão voltados ao resultado.

A atual metodologia de distribuição de recursos orçamentários entre as universidades, denominados de Orçamento de Custeios e Capital (OCC), é composta por dois componentes: o Orçamento de Manutenção, ou Orçamento Básico e o Orçamento de Investimento. O Orçamento Básico é dividido em duas parcelas, uma correspondente a $80 \%$ desse valor sendo destinada a manutenção da IFES, cujo cálculo é multiplicação entre a Unidade Básica de Custeio (UBC) e o número de alunos equivalentes de cada unidade. Os $20 \%$ restante, denominada Parcela de Qualidade e Produtividade (IQP), é destinada considerando diversos indicadores qualitativos (BRASIL, 2006).

O modelo de alocação proposto na Figura 2 visa distribuir os recursos orçamentários para realização das despesas de custeio e investimento das universidades, ou seja, do orçamento total da universidade exclui-se os recursos destinados a despesas relacionadas com pessoal (REIS et al., 2017).

Utilizar um modelo para alocar os recursos orçamentários nas Universidades Federais é uma demonstração por parte da administração pública para institucionalizar uma ferramenta que possa promover maior controle e eficiência na gestão de recursos públicos e na gestão universitária (REIS et al., 2017).

O principal indicador utilizado para fins de análise dos custos de manutenção das IFES referentes ao orçamento de custeio e capital (OCC) é o Número de Aluno-Equivalente (NAE), esse cálculo agrega quatro indicadores parciais, referentes às atividades educacionais nos níveis de graduação, mestrado, doutorado e residência médica (BRASIL, 2006). 
Para o cálculo do NAE de graduação, são considerados o número de diplomados, a duração média do curso, um coeficiente de retenção, o número de alunos ingressantes, um bônus de $10 \%$ por turno noturno, um bônus de $15 \%$ por curso fora de sede e um coeficiente denominado Peso do Grupo.

Figura 2 - Modelo de alocação de OCC

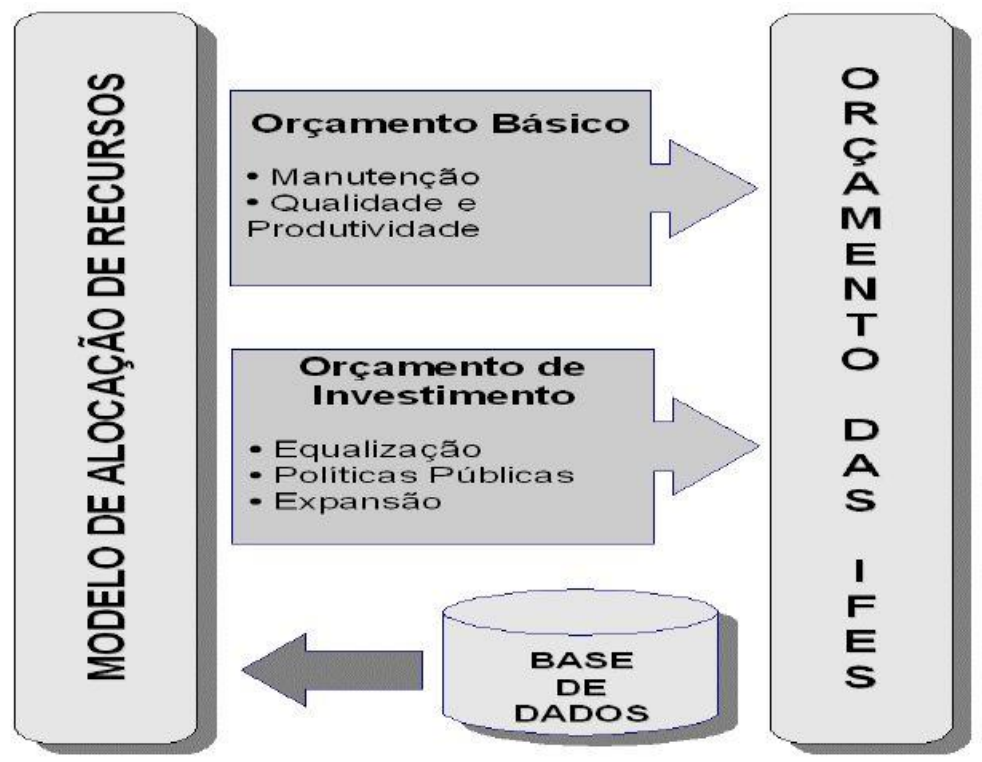

Fonte: Brasil, 2006

Quanto ao cálculo do NAE de mestrado, leva-se em consideração o número de alunos matriculados efetivos do mestrado, o tempo dedicado a cursar as disciplinas e o coeficiente denominado Peso do Grupo.

Já para o cálculo do NAE de doutorado são considerados os seguintes indicadores: o número de alunos matriculados efetivos do doutorado, o tempo dedicado a cursar as disciplinas e o coeficiente denominado Peso do Grupo.

O NAE de residência médica corresponde exatamente ao número de alunos matriculados nos Programas de Residência Médica.

Para efetuar o cálculo do aluno equivalente total, soma-se os alunos equivalentes dos diversos níveis de escolaridade existentes na educação superior brasileira, graduação, mestrado, doutorado e residência médica.

O planejamento financeiro é considerado um dos principais instrumentos de gestão educacional das organizações de ensino superior, e este inicia-se com a elaboração do orçamento, que é uma ferramenta indispensável para a administração da instituição de ensino e que serve para prever as necessidades econômicas e financeiras. 
Segundo Ching (2006) muitas pessoas costumam associar a palavra "orçamento" à limitações de gastos, no entanto, orçamento vai muito além da limitação dos gastos. É uma ferramenta que ajuda os gestores, de empresas privadas ou governamentais, em suas funções de planejamento e controle, na gestão financeira e na previsão dos resultados operacionais.

No sentido de projeção, previsão, simulação, programação, dentre outros conceitos similares, Padoveze e Taranto (2009) definem orçamento como o ato de colocar à frente aquilo que está acontecendo hoje, mas o orçamento tem um potencial enorme e não é somente empregado como uma metodologia em que os gestores planejam visualizando o futuro, mas também, quando necessário, ser utilizado para avaliar o desempenho passado (CHING, 2006).

A gestão financeira e orçamentária das IES deve ser realizada a fim de garantir a sustentabilidade da organização. São diversos indicadores que devem ser utilizados para a tomada de decisão. Eles são empregados para auxiliar os gestores educacionais no bom funcionamento da organização e que permita que todos tenham uma visão sistêmica da gestão escolar (QUEIROZ et al., 2011).

Considerando as particularidades das instituições de ensino, Merchede e Moreira (2011) demonstram, em linhas gerais, as principais fontes de saída de recursos financeiros. De maneira genérica, são quatro áreas que consomem os recursos financeiro das IES por meio das atividades de ensino, são elas: Pessoal, Material, Serviços de Terceiros e CAPEX, ilustrado na Figura 2.

No plano orçamentário com pessoal deve incluir não somente os gastos com o corpo docente, mas também com o capital intelectual administrativo da organização educacional; o plano orçamentário de Materiais inclui a previsão de gastos com os diversos tipos de materiais de limpeza, bem como os materiais que são utilizados no dia-a-dia pelo público interno da IES; quanto ao plano de previsão de gastos com Serviços de Terceiros, diz respeito aqueles serviços definidos pela IES que exigem uma atuação mais especializada, enquanto concentra-se suas energias na atividade principal; e o termo CAPEX é a sigla para a expressão inglesa "Capital Expenditure", que representa a quantidade de recursos financeiros que são alocados na compra de bens de capital de uma determinada companhia, ou seja, reflete o montante de investimento aplicado em equipamentos e instalações de forma a manter o funcionamento um negócio.

Obviamente a ilustração (Figura 3) demonstra as principais fontes de saída de recursos financeiros, no entanto, é indispensável a realização do plano de entrada de recursos, que é o orçamento de vendas, para o caso das instituições privadas. 
Figura 3 - Fluxos de gastos nas organizações universitárias

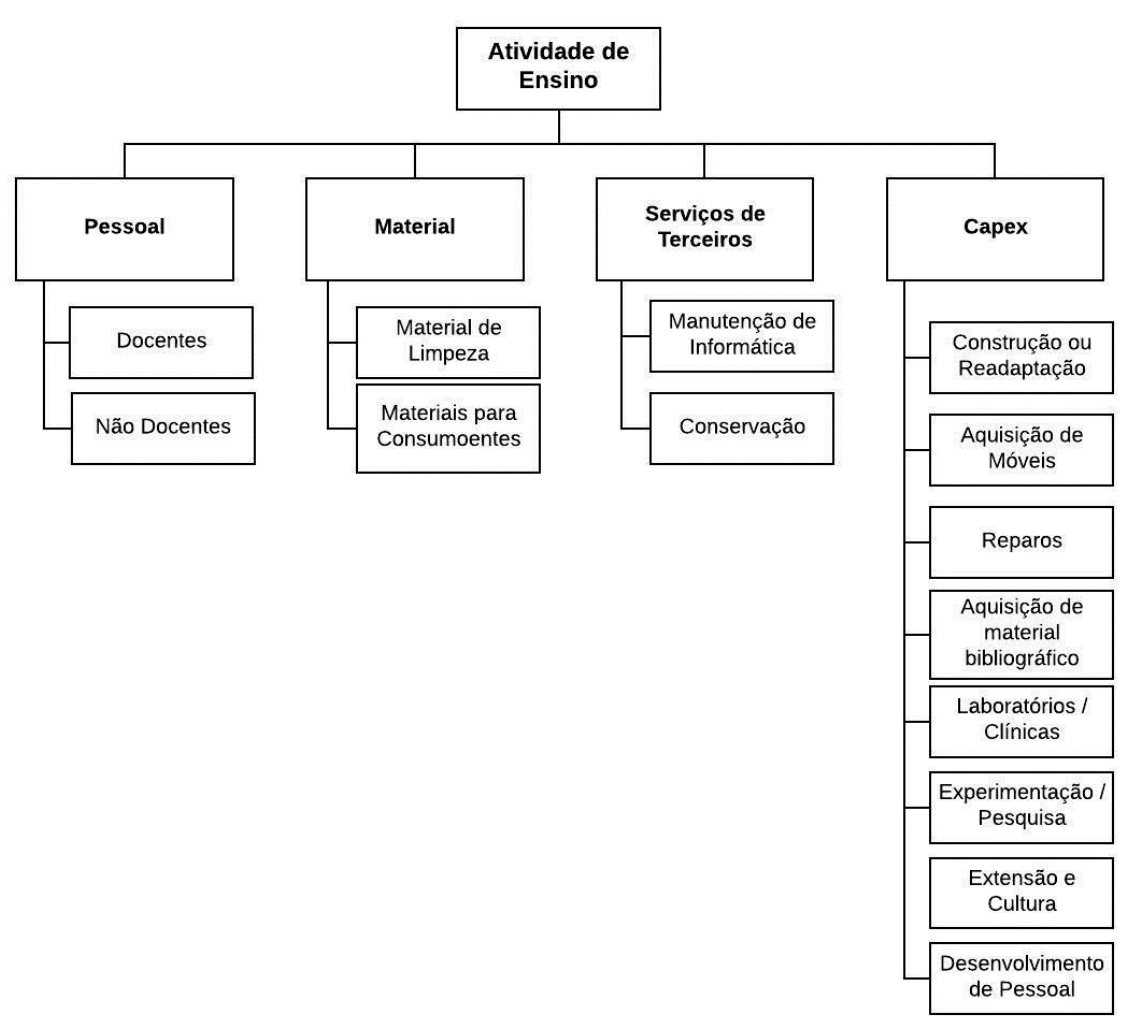

Fonte: Elaborado a partir de Merchede e Moreira, 2011

Nessa linha de pensamento cabem aos gestores controlar as variáveis desse fluxo de maneira que possa melhorar os resultados, visto que estes só serão factíveis em uma janela temporal de médio a longo prazo.

A primeira etapa do estudo consistiu em realizar uma pesquisa bibliográfica, que compreendia a identificação, a filtragem e a seleção das publicações, conforme o diagrama do fluxo ilustrado na Figura 1.

A coleta inicial de dados (identificação) se deu por meio do Portal de Periódicos CAPES/MEC, na Rede SciELO e no Google Acadêmico. Na filtragem dos dados foram empregados operadores lógicos, também conhecidos como operadores booleanos. Os operadores booleanos são usados para definir relações entre termos em uma pesquisa, a fim de ampliar ou restringir os resultados (BLUM et al., 2016; PALMA et al., 2018). E para saber se os artigos selecionados atendiam os requisitos exigidos da pesquisa, eram analisados o título, o resumo, as palavras-chaves e a leitura da publicação.

A pesquisa realizada no Portal Periódicos Capes utilizou-se como parâmetro de pesquisa as seguintes palavras-chaves: "orçamento custeio", "distribuição orçamentária", "alocação orçamentária", "matriz orçamentária" e "modelo orçamentário", todas acompanhadas da 
palavra "universidade", utilizando o operador booleano "AND". Do total de artigos, inicialmente identificados, nenhum atendia os critérios estabelecidos, conforme ilustração da Tabela 2.

Tabela 2 - Número de artigos publicados no Portal CAPES/MEC sobre rateio orçamentário das IES do Brasil - Brasil - 2014-2018

\begin{tabular}{|c|c|c|c|c|c|}
\hline Parâmetro da Pesquisa & $\begin{array}{c}\text { Resultado } \\
\text { Inicial }\end{array}$ & $\begin{array}{l}\text { Revisados } \\
\text { por Pares }\end{array}$ & Brasil & $\begin{array}{c}2014 a \\
2018\end{array}$ & $\begin{array}{c}\text { Resultado } \\
\text { Final }\end{array}$ \\
\hline (orçamento custeio) AND universidade & 255 & 172 & 49 & 29 & 0 \\
\hline (distribuição orçamentária) AND universidade & 485 & 334 & 117 & 68 & 0 \\
\hline (alocação orçamentária) AND universidade & 246 & 178 & 68 & 36 & 0 \\
\hline (matriz orçamentária) AND universidade & 167 & 114 & 39 & 22 & 0 \\
\hline (modelo orçamentário) AND universidade & 358 & 234 & 62 & 35 & 0 \\
\hline
\end{tabular}

Fonte: Elaborado pelos autores, 2018

Não obtendo resultados favoráveis no portal da CAPES/MEC, a investigação passou-se para o Portal da Rede Scientific Electronic Library Online (SciELO). Nesse portal a pesquisa centrou-se nas palavras-chaves em português, utilizando-se a opção de busca pelo método integrado, que busca na própria base SciELO e pesquisa Regional, que destaca a busca na totalidade do portal. Do total de artigos, inicialmente identificados, nenhum atendia os critérios estabelecidos, conforme ilustra a Tabela 3.

Tabela 3 - Número de artigos publicados no Portal SciELO sobre rateio orçamentário das IES do Brasil Pesquisa em português - Método: integrada - Pesquisa Regional - Brasil 2014-2018

\begin{tabular}{cccccc} 
Parâmetro da Pesquisa & $\begin{array}{c}\text { Resultado } \\
\text { Inicial }\end{array}$ & $\begin{array}{c}\text { Revisados } \\
\text { por Pares }\end{array}$ & $\begin{array}{c}\text { Brasil } \\
\mathbf{2 0 1 4} \text { a }\end{array}$ & $\begin{array}{c}\text { Resultado } \\
\text { Final }\end{array}$ \\
\hline (orçamento custeio) AND universidade & 0 & Inexiste & 0 & 0 & 0 \\
(distribuição orçamentária) AND universidade & 0 & Inexiste & 0 & 0 & 0 \\
(alocação orçamentária) AND universidade & 0 & Inexiste & 0 & 0 & 0 \\
(matriz orçamentária) AND universidade & 0 & Inexiste & 0 & 0 & 0 \\
(modelo orçamentário) AND universidade & 0 & Inexiste & 0 & 0 & 0 \\
\hline
\end{tabular}

Fonte: Elaborado pelos autores, 2018

Para se obter um maior alcance de resultados, ainda no Portal SciELO, utilizou-se as palavras-chaves em inglês utilizando-se a opção de busca pelo método integrado e pesquisa Regional. Do total de artigos, inicialmente identificados, nenhum atendia os critérios estabelecidos, conforme ilustra a Tabela 4. 
Tabela 4 - Número de artigos publicados no Portal SciELO sobre rateio orçamentário das IES do Brasil Pesquisa em inglês - Método: integrada - Pesquisa Regional - Brasil 2014-2018

\begin{tabular}{|cccccc}
\hline Parâmetro da Pesquisa & $\begin{array}{c}\text { Resultado } \\
\text { Inicial }\end{array}$ & $\begin{array}{c}\text { Revisados } \\
\text { por Pares }\end{array}$ & Brasil & $\begin{array}{c}\text { 2014 a } \\
\mathbf{2 0 1 8}\end{array}$ & $\begin{array}{c}\text { Resultado } \\
\text { Final }\end{array}$ \\
\hline budget costing AND university & 1 & Inexiste & 0 & 0 & 0 \\
budget distribution AND university & 4 & Inexiste & 1 & 0 & 0 \\
\hline budget allocation AND university & 2 & Inexiste & 1 & 0 & 0 \\
budget matrix AND university & 0 & Inexiste & 0 & 0 & 0 \\
budget model AND university & 11 & Inexiste & 6 & 1 & 0 \\
\hline
\end{tabular}

Fonte: Elaborado pelos autores, 2018

Legenda:

budget costing - orçamento custeio

budget distribution - distribuição orçamentária

budget allocation - alocação orçamentária

budget matrix - matriz orçamentária

budget model - modelo orçamentário

university - universidade

Ainda no Portal SciELO, foram realizados dois tipos de buscas pelo método Google Acadêmico, uma pesquisa em português e uma em inglês, registradas nas Tabelas 5 e 6 . Após as exclusões e artigos em duplicidade, restaram quatro publicações que atendiam aos requisitos da pesquisa.

Tabela 5 - Número de artigos publicados no Portal SciELO sobre rateio orçamentário das IES do Brasil -

Pesquisa em português - Método: Google Acadêmico - Pesquisa Regional - Brasil 2014-2018

\begin{tabular}{cccccc}
\hline Parâmetro da Pesquisa & $\begin{array}{c}\text { Resultado } \\
\text { Inicial }\end{array}$ & $\begin{array}{c}\text { Revisados } \\
\text { por Pares }\end{array}$ & Brasil & $\begin{array}{c}\text { 2014 a } \\
\mathbf{2 0 1 8}\end{array}$ & $\begin{array}{c}\text { Resultado } \\
\text { Final }\end{array}$ \\
\hline (orçamento custeio) AND universidade & 12 & Inexiste & 12 & 9 & 0 \\
\hline (distribuição orçamentária) AND universidade & 112 & Inexiste & 101 & 45 & 4 \\
(alocação orçamentária) AND universidade & 148 & Inexiste & 137 & 68 & $1 *$ \\
(matriz orçamentária) AND universidade & 112 & Inexiste & 102 & 65 & $2 *$ \\
(modelo orçamentário) AND universidade & 79 & Inexiste & 69 & 37 & $2 *$ \\
\hline
\end{tabular}

Fonte: Elaborado pelos autores, 2018

* Publicações em duplicidade, computado no parâmetro “distribuição orçamentária”.

Após selecionar as quatro publicações que atendiam aos requisitos pré-estabelecidos na pesquisa, passou-se a fase de leitura qualitativa e análise crítica. Para cada publicação elaborouse um quadro informativo com os principais dados bibliográficos a fim de auxiliar no exame pormenorizado do escrito científico. 
Tabela 6 - Número de artigos publicados no Portal SciELO sobre rateio orçamentário das IES do Brasil Pesquisa em inglês - Método: Google Acadêmico - Pesquisa Regional - Brasil 2014-2018

\begin{tabular}{|cccccc}
\hline Parâmetro da Pesquisa & $\begin{array}{c}\text { Resultado } \\
\text { Inicial }\end{array}$ & $\begin{array}{c}\text { Revisados } \\
\text { por Pares }\end{array}$ & Brasil & $\begin{array}{c}\mathbf{2 0 1 4} \text { a } \\
\mathbf{2 0 1 8}\end{array}$ & $\begin{array}{c}\text { Resultado } \\
\text { Final }\end{array}$ \\
\hline budget costing AND university & 1 & Inexiste & 0 & 0 & 0 \\
budget distribution AND university & 10 & Inexiste & 2 & 2 & 0 \\
\hline budget allocation AND university & 267 & Inexiste & 40 & 23 & $1 *$ \\
budget matrix AND university & 4 & Inexiste & 1 & 6 & 0 \\
\hline budget model AND university & 44 & Inexiste & 6 & 0 \\
\hline
\end{tabular}

Fonte: Elaborado pelos autores, 2018

* Publicação em duplicidade, computado no parâmetro "distribuição orçamentária".

\section{Legenda:}

budget costing - orçamento custeio

budget distribution - distribuição orçamentária

budget allocation - alocação orçamentária

budget matrix - matriz orçamentária

budget model - modelo orçamentário

university - universidade

A Publicação 1 apresentou como situação-problema de pesquisa, de forma a identificar como está estruturado o processo de execução orçamentária do Centro de Ciência da Saúde da Universidade Federal de Santa Maria e para isso objetivou mapear seus processos de execução orçamentária.

Quadro 1 - Quadro Informativo da Publicação 1

\begin{tabular}{|c|l|}
\hline Referência & Publicação 1 \\
\hline Autoria & Rochele Santos Silva \\
\hline Título & $\begin{array}{l}\text { O mapeamento dos processos orçamentários do Centro de Ciência da } \\
\text { Saúde da Universidade Federal de Santa Maria (UFSM) }\end{array}$ \\
\hline Tipo & Dissertação de mestrado \\
\hline Local & Santa Maria / Rio Grande do Sul \\
\hline IES & Universidade Federal de Santa Maria (UFSM) \\
\hline Ano & 2016 \\
\hline
\end{tabular}

Fonte: dados da pesquisa

Segundo Silva (2016) "A alocação dos gastos do Governo Federal na UFSM é determinada a partir de uma fórmula acordada no Ministério da Educação, denominada de Índice de Distribuição de Recursos (IDR)". Para a distribuição do IDR, leva-se em consideração o desempenho das unidades da instituição em quatro grupos: retrospecto, ensino, pesquisa e extensão. Cabe à Pró-Reitoria de Planejamento (PROPLAN) a distribuição de recursos 
orçamentários, com base no IDR, de forma a incentivar a produção, produtividade e políticas de desenvolvimento da instituição.

Destaca-se, ainda, que a partir de 2015 a IES passa a adotar a fórmula com base no cálculo da ANDIFES, a qual considera o número de alunos matriculados em cada curso e o peso específico do grupo.

Quadro 2 - Quadro Informativo da Publicação 2

\begin{tabular}{|c|l|}
\hline Referência & Publicação 2 \\
\hline Autoria & Marluce Braz Duarte \\
\hline Título & $\begin{array}{l}\text { A execução orçamentária do Instituto Federal de Educação, Ciência e } \\
\text { Tecnologia do Norte de Minas Gerais, no período de 2012 a 2015 }\end{array}$ \\
\hline Tipo & Dissertação de mestrado \\
\hline Local & Teófilo Otoni / Minas Gerais \\
\hline IES & Universidade Federal dos Vales do Jequitinhonha e Mucuri (UFVJM) \\
\hline Ano & 2017 \\
\hline
\end{tabular}

Fonte: dados da pesquisa

A situação-problema de pesquisa da Publicação 2 foi analisar o desempenho da execução orçamentária do Instituto Federal de Educação, Ciência e Tecnologia do Norte de Minas Gerais, no período de 2012 a 2015.

Os procedimentos orçamentários e financeiros relacionados à autonomia dos institutos federais de educação, ciência e tecnologia são regidos pelo Decreto ${ }^{\circ} 7.313$, de 2010 , no entanto a elaboração da Matriz Orçamentária é feita por uma comissão de membros do Fórum de Planejamento (FORPLAN), que é um órgão de natureza consultiva e de assessoramento do Conselho Nacional das Instituições da Rede Federal de Educação Profissional, Científica e Tecnológica (CONIF).

De acordo com a pesquisa de Duarte (2017), desde 2010 o CONIF por meio do FORPLAN, vem utilizando essa metodologia, com algumas atualizações feitas anualmente, a fim de propor os valores orçamentários que devem ser destinados aos Institutos Federais de Educação.

Quadro 3 - Quadro Informativo da Publicação 3

\begin{tabular}{|c|l|}
\hline Referência & Publicação 3 \\
\hline Autoria & Rodrigo Soares Lelis Gori \\
\hline Título & $\begin{array}{l}\text { Modelo de distribuição de recursos orçamentários baseado em indicadores } \\
\text { de desempenho para um instituto federal de educação, ciência e tecnologia }\end{array}$ \\
\hline Tipo & Dissertação de mestrado \\
\hline Local & São Leopoldo / Rio Grande do Sul \\
\hline IES & Universidade do Vale do Rio dos Sinos (UNISINOS) \\
\hline Ano & 2016 \\
\hline
\end{tabular}

Fonte: dados da pesquisa 
Analisando mais criticamente o objetivo geral da Publicação 3, verificou-se que a ideia foi propor um modelo de distribuição de recursos orçamentários, baseado em indicadores de desempenho para unidades de ensino que compõem um Instituto Federal de Educação, Ciência e Tecnologia, ao explorar o escopo integral do estudo, constatou-se que não atende aos prérequisitos estabelecidos na proposta da presente pesquisa.

Quadro 4 - Quadro Informativo da Publicação 4

\begin{tabular}{|c|l|}
\hline Referência & Publicação 4 \\
\hline Autoria & Edvan Santana Alves \\
\hline Título & $\begin{array}{l}\text { Um estudo sobre a alocação interna dos recursos orçamentários nas } \\
\text { universidades federais brasileiras }\end{array}$ \\
\hline Tipo & Dissertação de mestrado \\
\hline Local & Salvador / Bahia \\
\hline IES & Universidade Federal da Bahia \\
\hline Ano & 2016 \\
\hline
\end{tabular}

Fonte: dados da pesquisa

A Publicação 4 teve como objetivos centrais investigar e analisar as metodologias internas de alocação dos recursos orçamentários praticadas nas Universidades Federais do Brasil, além de propor uma matriz própria para alocação interna desses recursos.

Nesse estudo Alves (2016) compara os modelos adotados por doze Universidades Federais do Brasil, realiza uma crítica ao conjunto de modelos para posteriormente propor uma matriz de distribuição desses recursos.

Sintetizando a avaliação dos modelos estudados por Alves (2016) "é possível comparar os modelos estudados entre si e cotejá-los com os conceitos presentes na Matriz ANDIFES utilizada pela SESu/MEC para alocação dos recursos orçamentários às Universidades Federais", observa-se, portanto, que apesar das particularidades de cada instituição e dos diferentes modelos, é possível perceber que seus orçamentos são sustentados no modelo de alocação de recursos orçamentários estipulado pela Secretaria de Educação Superior (SESu) do MEC em parceria com a Associação Nacional de Dirigentes das Instituições Federais de Ensino Superior (ANDIFES), chamado de Matriz de Outros Custeios e Capital (OCC).

Quanto às Instituições Privadas de Ensino Superior buscou-se pesquisar as empresas listadas no sítio eletrônico da Brasil Bolsa Balcão, visto que todas as empresas listadas na Bovespa são obrigadas a divulgar determinadas informações aos investidores preconizadas pela legislação vigente. 
As empresas listadas na Bovespa no Segmento de Serviços Educacionais são: Anima Holding S.A., Bahema S.A., Estácio Participações S.A., Kroton Educacional S.A., Ser Educacional S.A., Somos Educação S.A., conforme Quadro 5.

Quadro 5 - Empresas listadas na Bovespa no segmento de Serviços Educacionais

\begin{tabular}{|c|c|c|}
\multicolumn{2}{|c|}{ Setor } & Razão Social \\
\hline \multirow{3}{*}{ Consumo Cíclico } & Serviços Educacionais & Anima Holding S.A. \\
& & Bahema S.A. \\
& & Estácio Participações S.A. \\
& & Kroton Educacional S.A. \\
& & Ser Educacional S.A. \\
\hline
\end{tabular}

Fonte: dados da pesquisa

Foram analisadas as informações disponibilizadas no sítio eletrônicos das empresas, no canal de relacionamento com investidores, bem como os relatórios estruturados, as apresentações institucionais de resultados do terceiro trimestre de 2018, além dos dados econômico-financeiros das empresas listadas no Quadro 5.

As empresas Anima Holding S.A., Estácio Participações S.A. e Kroton Educacional S.A. não disponibilizam informações relativas aos critérios pré-estabelecidos na pesquisa.

Bahema S.A. e Somos Educação S.A. são empresas que atuam na educação básica, portanto, não atendem aos critérios pré-estabelecidos na pesquisa.

Das empresas pesquisadas, a Ser Educacional S.A. adota um modelo de Orçamento Matricial para o rateio de seus gastos, conforme representado na Figura 4.

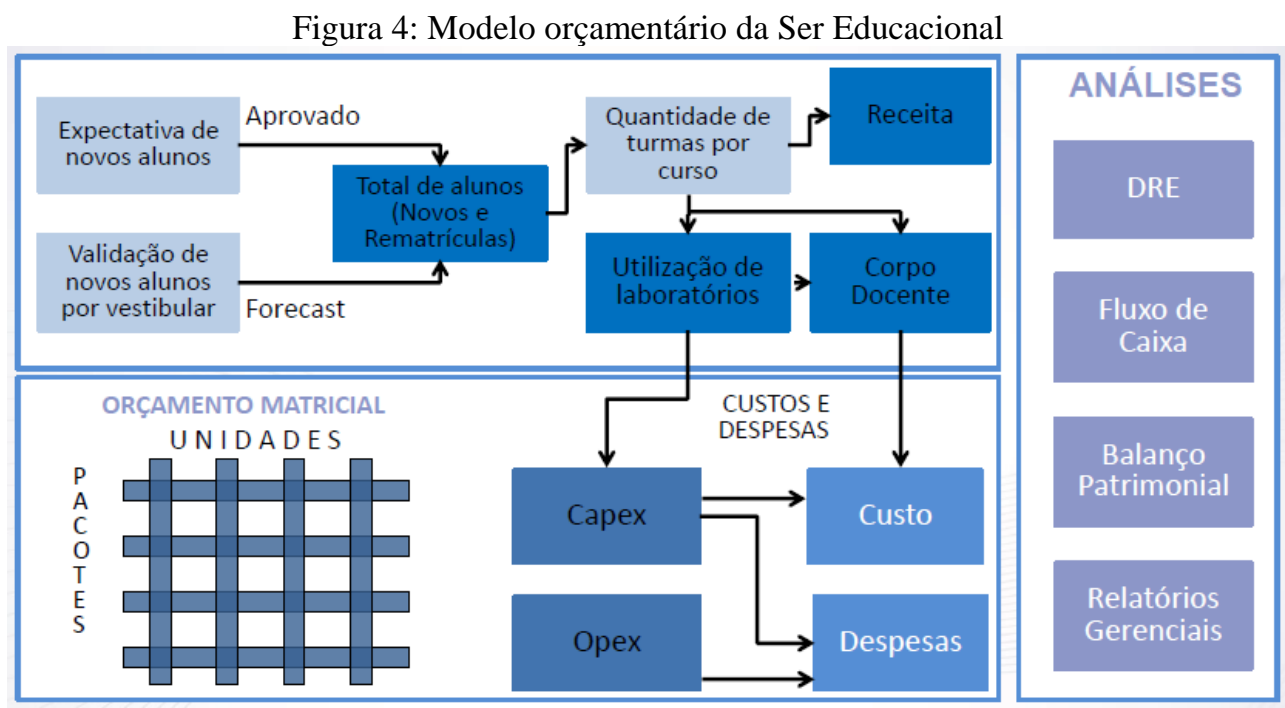

Fonte: Ser Educacional, (2014). 
O Orçamento Matricial ou Gerenciamento Matricial de Despesas, é recomendado para as empresas que procuram constantemente acompanhar seus custos, de forma a tornar a empresa mais competitiva em termos de preço, qualidade dos serviços ofertados (VOLTZ et al., 2017). Este é um dos mais recentes conceitos de controle orçamentário, pois defende um duplo controle nos principais elementos de receitas e de despesas (PADOVEZE e TARANTO, 2009).

As notícias que são divulgadas ao público pelas empresas privadas, em geral, são as previstas em legislação. As de natureza gerencial, ou seja, são informações de cunho estratégicos para o crescimento da empesa, portanto, não são difundidas e consequentemente um alto grau de dificuldade em obter dados para a pesquisa.

\section{CONCLUSÃO}

Esta pesquisa foi desenvolvida no intuito de apresentar um estudo sobre os modelos de orçamento custeio de Instituições de Ensino Superior no Brasil, com foco no âmbito da gestão orçamentária. Após analisar os modelos de distribuição orçamentária das instituições de ensino superior no Brasil algumas constatações podem ser apresentadas, para as quais devem ser considerados os pré-requisitos estabelecidos nesta pesquisa.

A apresentação e a análise dos dados evidenciaram que somente quatro publicações atenderam aos parâmetros definidos para a pesquisa. O tipo de publicação, porém, chama a atenção, pois as quatro publicações selecionadas para a análise qualitativa são dissertações de mestrado, e, ainda, os estudos foram realizados em instituições públicas de ensino superior.

Outro viés dado a pesquisa foi quanto às Instituições Privadas de Ensino Superior, que devido ao alto grau de dificuldade em obter dados para a pesquisa, buscou-se minerar informações das empresas listadas na Bovespa, visto que essas empresas são obrigadas a divulgar notícias relevantes aos investidores.

O estudo constatou, ainda, que as Instituições Públicas de Ensino Superior adotam, com algumas variações, o modelo proposto pelo MEC e pela Associação Nacional de Dirigentes das Instituições Federais de Ensino Superior (ANDIFES). Quanto aos modelos adotados pelas Instituições Privadas de Ensino Superior, apenas em uma foi possível realizar a análise, e esta adota um modelo de Orçamento Matricial.

Ao longo da realização desta pesquisa, constatou-se a carência de estudos sobre matriz orçamentária de Instituições Privadas de Ensino Superior. Nesse sentido, sugere-se investigações mais aprofundadas relacionadas as práticas de alocação orçamentárias adotadas por essas IES. 


\section{REFERÊNCIAS}

ALVES, Edvan Santana; Um estudo sobre a alocação interna dos recursos orçamentários nas universidades federais brasileiras; Orientador: Marcelo Embiruçu; Dissertação de mestrado; Universidade Federal da Bahia; Salvador. 2016.

ARAÚJO, F. J. A.; CABRAL, A. C. A.; SANTOS, S. M.; PESSOA, M. N. M.; Gestão Estratégica em Instituições Privadas de Ensino Superior. Revista GUAL, Florianópolis, v. 11, n. 1, p. 71-91, janeiro, 2018.

BLUM, Arina; ANDRÉS DÍAZ MERINO, Eugenio; ALVES DÍAZ MERINO, Giselle Schmidt. Método visual para revisão sistemática em Design com base em conceitos da Mineração. DAPesquisa. v.11, n.16, p124-139, agosto 2016.

BRASIL. Decreto No 9.235, de 15 de dezembro de 2017, Brasília, DF, dez. 2017a.

BRASIL. Lei n. 10.861, de 14 de abr. de 2004. Sistema Nacional de Avaliação da Educação Superior - SINAES, Brasília, DF, abr. 2004a.

BRASIL - MINISTÉRIO DA EDUCAÇÃO - MEC. Instituto Nacional de Estudos e Pesquisas Educacionais Anísio Teixeira. Notas Estatísticas - Censo da Educação Superior 2017. Brasília, DF. 2017b.

BRASIL - MINISTÉRIO DA EDUCAÇÃO - MEC. Plano de Desenvolvimento Institucional (PDI) - Diretrizes para Elaboração. Brasília, DF, dez. 2004b.

BRASIL - MINISTÉRIO DA EDUCAÇÃO - MEC. Secretaria de Educação Superior. A coleta de dados das IFES para Alocação de Recursos Orçamentários. Brasília, 2006.

BRASIL BOLSA BALCÃO; Empresas listadas, Setor de Atuação; Disponível em: $<$ http://www.b3.com.br/pt_br/produtos-e-servicos/negociacao/renda-variavel/empresaslistadas.htm>; Acesso em: 15 dez. 2018.

CHANG, Alvin; CHAO, Chih-Yang; Budget Allocation for Information Logistics in Taiwanese University; Journal of Modern Accounting and Auditing, Vol. 12, No. 6, 344-353, June 2016.

DUARTE, Marluce Braz; A execução orçamentária do Instituto Federal de Educação, Ciência e Tecnologia do Norte de Minas Gerais, no período de 2012 a 2015; Orientador: Simão Pereira da Silva; Dissertação de mestrado; Universidade Federal dos Vales do Jequitinhonha e Mucuri. Teófilo Otoni. 2017.

GORI, Rodrigo Soares Lelis; Modelo de distribuição de recursos orçamentários baseado em indicadores de desempenho para um instituto federal de educação, ciência e tecnologia; Orientador: Daniel Pacheco Lacerda; Dissertação de mestrado; Universidade do Vale do Rio dos Sinos. São Leopoldo. 2016. 
GRIBOSKI, Claudia Maffini; PEIXOTO, Maria do Carmo de Lacerda; HORA, Paola Matos da; Avaliação externa, autoavaliação e o PDI; Avaliação, Campinas; Sorocaba, SP, v. 23, n. 1, p. 178-197, mar. 2018.

KNECHTEL, Maria do Rosário. Metodologia da pesquisa em educação uma abordagem teórico-prática dialogada [livro eletrônico]. Curitiba. InterSaberes, 2014.

MERCHEDE, Alberto; MOREIRA, Francisco Otávio. Custos e formação de preços para instituições de ensino: tributos e análise de investimentos. São Paulo: Atlas, 2011.

PADOVEZE, Clóvis Luiz; TARANTO, Fernando Cesar. Orçamento empresarial: novos conceitos e técnicas. São Paulo: Pearson Education do Brasil, 2009.

PALMA, Jessica Luciane; SANTOS, Ariane Cristina de Lima dos; JORDÃO, Sabrina Sena de; SOUSA, Raquel Juliana do Prado Leite de. AVALIAÇÃO DE REPOSITÓRIOS INSTITUCIONAIS: proposta de padronização de critérios. V Encontro Regional dos Estudantes de Biblioteconomia, Documentação, Gestão e Ciência da Informação das Regiões Sudeste, Centro-oeste e sul. Universidade Federal de Minas Gerais. 2018.

QUEIROZ, Fernanda Cristina Barbosa Pereira; QUEIROZ, Jamerson Viegas; HÉKIS, Hélio Roberto; GESTÃO ESTRATÉGICA E FINANCEIRA DAS INSTITUIÇÕES DE ENSINO SUPERIOR: UM ESTUDO DE CASO; Iberoamerican Journal of Industrial Engineering, Florianópolis, v. 3, n. 1, p. 98-117, julho, 2011.

REIS, Cisne Zélia Teixeira; OLIVEIRA, Adriel Rodrigues de; SILVEIRA, Suely de Fátima Ramos; CUNHA, Nina Rosa da Silveira. Modelo orçamentário das universidades federais: fatores motivadores e inibidores de sua institucionalização. Revista de Administração da Universidade Federal de Santa Maria, vol. 10, núm. 6, 2017, pp. 1081-1100. Universidade Federal de Santa Maria. Santa Maria, 2017.

SANTOS, Alexandre Rodrigues; MOURA, Heber José de. O Orçamento e o desempenho nas Universidades Federais entre 2005 a 2014. Revista FSA, Teresina, v. 14, n. 3, art. 1, p. 03 27, mai./jun. Brasil. 2017.

SER EDUCACIONAL; Viva Ser: encontro dos investidores; Apresentações e Teleconferências; Apresentação institucional Viva Ser. 16 set. 2014. Disponível em: < http://ri.sereducacional.com/sereducacional/web/conteudo_pt.asp?idioma=0\&conta=28\&tipo $=47941 \& \mathrm{id}=0 \&$ submenu $=0 \& \mathrm{img}=0 \&$ ano=2014 $>$; Acesso em: $10 \mathrm{dez} .2018$.

SILVA, Rochele Santos; O mapeamento dos processos orçamentários do Centro de Ciência da Saúde da Universidade Federal de Santa Maria (UFSM); Orientador: Reisoli Bender Filho; Dissertação (mestrado); Universidade Federal de Santa Maria (UFSM); Rio Grande do Sul. 2016.

VOLTZ, Marcos Fabrício; SCHMIDT, Paulo; DOS SANTOS, José Luiz. Orçamento base zero e orçamento matricial: vantagens e desvantagens de sua utilização. Caderno de Administração - v. 25, n. 1. 2017.

WERLANG, Elisabete. Revisão por pares: um estudo da gestão de avaliadores nas revistas científicas brasileiras. Universidade Federal de Santa Catarina. 2013. 